\title{
ARTE PÚblica URBANA E COMUNICAÇÃo TURÍSTICA
}

\author{
Pedro de Andrade \\ Centro de Estudos de Comunicação e Sociedade, Universidade do Minho, Portugal
}

\begin{abstract}
ReSUMO
O presente texto, por um lado, visa descortinar alguns dos debates recentes sobre a arte pública urbana, e as suas práticas mais criativas. Nesta perspetiva, apresenta-se um estudo de caso ilustrativo sobre o Iminente Festival enquanto interculturalidade imanente à arte pública. Em seguida, discute-se a e-arte pública, ou seja, a arte pública que é produzida e partilhada no ciberespaço e no cibertempo. Depois, estas iniciativas artísticas são confrontadas com controvérsias, clássicas e atuais, acerca das culturas móveis como o turismo e, em especial, o processo da comunicação turística. Novas epistemologias e metodologias sociológicas encontram-se igualmente abordadas, e exemplificadas com a Sociologia Artística, a Hibridologia e a Banda Desenhada Sociológica. Finalmente, um breve glossário busca sintetizar e definir alguns conceitos sociológicos que circunscrevem processos sociais centrais, subjacentes à articulação e hibridação entre a arte pública urbana e a comunicação turística.
\end{abstract}

\section{Palavras-Chave}

arte pública urbana; comunicação turística; cidade 3.0; turismo comunicativo; web 3.0

\section{URBAN PUBLIC ART AND TOURISM COMMUNICATION}

\begin{abstract}
The present text, on the one hand, aims to unveil some of the most recent debates on urban public art, and its most creative practices. In this perspective, an illustrative case study about the Imminent Festival is presented as interculturality immanent to public art. Then, public e-art is discussed, that is, public art that is produced and shared in cyberspace and cybertime. And these artistic initiatives are confronted with controversies, classic and current, about mobile cultures such as tourism and, in particular, the tourist communication process. New epistemologies and sociological methodologies are also addressed, and exemplified with Artistic Sociology, Hybridology and Sociological Comics. Finally, a brief glossary seeks to synthesize and define some sociological concepts that circumscribe central social processes, underlying the articulation and hybridization between urban public art and tourist communication.
\end{abstract}

\section{KEYWORDS}

urban public art; tourism communication; city 3.0; communicative tourism; web 3.0 


\section{INTRODUÇÃo}

A vida quotidiana no mundo contemporâneo oscila entre o espaço público urbano e o ciberespaço público digital (Andrade, 2012). A arte pública insere-se neste contexto, refletindo conflitos e consensos entre estas duas esferas da sociedade. O presente artigo visa a desconstrução e a reconstrução de algumas das manifestações de um tal embate social e do respetivo debate sociológico.

Em primeiro lugar, colocaremos algumas questões prévias sobre os modos de existência, experiência e consciência, no que respeita à proliferação e partilha da arte pública pré-digital, bem como da recente arte pública digital no seio do ciberespaço e do cibertempo. Uma tal dialética será ilustrada através de um estudo de caso sobre o evento de arte urbana nomeado "Iminente Festival", organizado pela associação cultural Underdogs. Este coletivo de artistas transformou-se numa das referências obrigatórias para o entendimento das culturas populares e artes urbanas em Portugal, e um estimulante objeto de estudos sociológico.

Em terceiro lugar, apresentaremos algumas recentes teorias e metodologias interativas fundamentais para a investigação, o ensino e a disseminação da arte pública aplicada à comunicação turística, visando essencialmente três audiências de leitores: cidadãos, turistas e migrantes.

Por fim, uma breve definição de alguns destes fenómenos ascendentes, discutidos com mais pormenor no corpo do texto, encontra-se no glossário em anexo, como os termos "arte pública" (pré-digital e digital), "cidade 3.0", "smart city", "cidade criativa", "cultura 3.0", "públicos da arte pública", "turismo 3.0", "turismo comunicativo", "turismo criativo", "turismo cultural" (pré-digital e digital), "turismo inovador", "web 2.0" ou "web social", "web 3.0" ou "web social-semântica".

\section{UM BREVE ESTUdo DE CASO: O IMINENTE FESTIVAL ENQUANTO INTERCULTURALIDAde IMANENTE}

Há cerca de dez anos, foi realizada noutro lugar a necessária discussão prévia, sociológica e histórica, quando à arte pública produzida e disseminada no espaço público urbano pré-digital, num livro coletivo que esgotou rapidamente e de que saiu uma $2^{\text {a }}$ edição em 2019. Aí, e quanto à vertente teórica desta problemática, o autor convocou os principais conceitos relacionados com a arte pública, como o património e políticas culturais, desenvolvimento urbano, cidades criativas, cidadania e turismo culturais (Andrade, 2010a). Para além disso, na sua componente pragmática, esses debates foram ilustrados com menções a estudos de caso e atividades práticas, por exemplo os movimentos socioculturais protagonizados por alteridades e interculturalidades urbanas (murais políticos, graffiti de minorias étnicas e de imigrantes) (Andrade, 2010b). Outro estudo relevante nesta direção é o ensaio de Idalina Conde (2010) sobre o contraste entre as narrativas artísticas no espaço público. 
No seguimento destas e de outras fundações, apresenta-se aqui uma ilustração recente de arte pública, na forma de introdução à parte de um estudo de caso sobre o Iminente Festival Urbano de Arte e Música'. Este evento, após várias edições em Oeiras, Londres, Xangai e Rio de Janeiro, foi realizado em Lisboa em 2018 e de novo entre 19 e 22 setembro de 2019, no antigo Restaurante Panorâmico de Monsanto, transformado hoje em ágora cultural e turística para atividades da arte pública e música urbana.

O Iminente Festival encerra uma natureza intercultural, tendo apresentado exposições, instalações, performances, concertos, etc., a um público formado por habitantes de várias cidades Portuguesas, turistas e imigrantes. Um aspeto a destacar, enquanto traço distintivo da cultura urbana atual, é a utilização frequente de dispositivos móveis digitais pelos visitantes, na sua relação interpessoal e no seio de atividades coletivas no espaço público envolvente. Através destes agentes sociais, o modo de comunicação digital dialoga com outros dois principais: o modo de comunicação face-a-face em copresença e o modo veiculado pelos meios de comunicação de massa, como os jornais, a rádio ou a televisão. Este Festival teceu uma configuração poderosa de intervenção na esfera pública cultural e democrática, por intermédio da coocorrência e hibridização de atividades da arte pública múltiplas e diferenciadas, mas igualmente interconectadas. Por exemplo, em termos de cultura democrática de intervenção política, ocorreram vários debates e uma discussão pública sobre o colonialismo Português, que reuniu diversos membros das culturas lusófonas, portugueses e intervenientes de origem africana (Figura 1).

Quanto às artes públicas visuais, ocorreram exposições variadas, como a mostra do conjunto de esculturas e murais à entrada do edifício principal (Figuras 2 e 3). Para além disso, ocorreu uma exposição e venda de pinturas, livros e catálogos, numa sala interior (Figura 4). Estas atividades foram organizadas pelo coletivo Underdogs (2020), uma associação e plataforma cultural com sede em Lisboa, que subscreve três objetivos centrais: um programa da arte pública, uma galeria de arte e a publicação de livros artísticos. Na Figura 5, repara-se no visionamento, por parte dos visitantes em co-presença, de quadros em ligação com a respetiva visão do mundo ativada via telemóvel, muito comum nos jovens. De facto, estes fruidores da exposição de arte comunicam face a face, mas amiúde em articulação com uma comunicação digital via dispositivos móveis digitais e locativos, seja para telefonemas exteriores ou outros usos (Figura 6), seja para a consulta de informação sobre a exposição (Figura 7). Outra expressão artística visual e gráfica, os graffitis e stênceis, abundam neste espaço-tempo intercultural, como aquele intitulado "Make the world Greta again" (Figura 8), e outros que exibem breves aforismos sobre o papel do artista e a essência ou a situação da criatividade urbana (Figura 9).

' Disponível em https://www.festivaliminente.com 


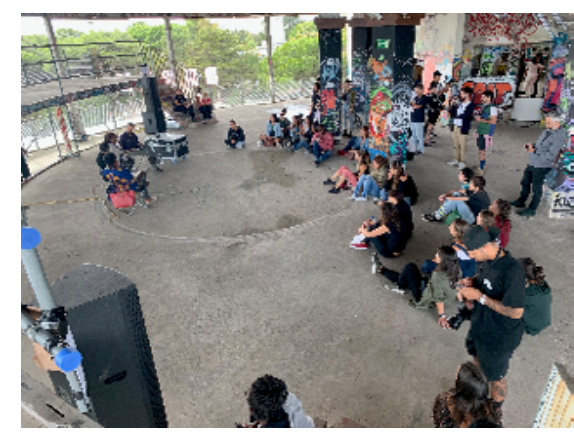

Figura 1: Debate de combate anticolonialista Créditos: Pedro Andrade

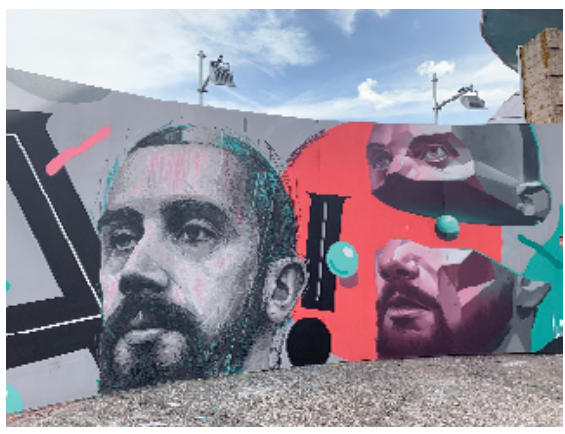

Figura 3: Murais figurativos ou abstratos Créditos: Pedro Andrade

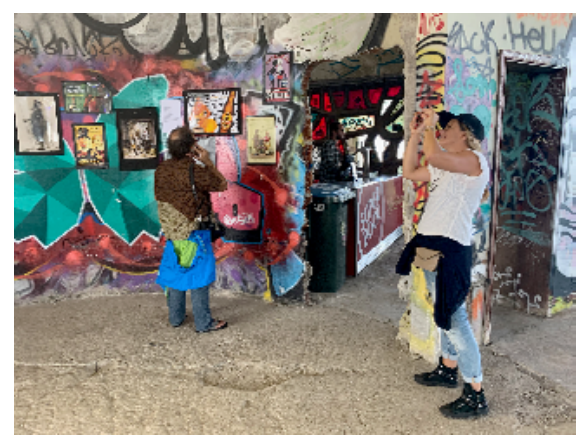

Figura 5: Fruição da arte via telemóvel Créditos: Pedro Andrade

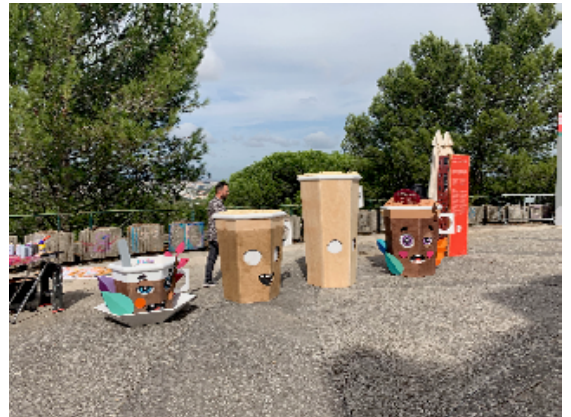

Figura 2: Esculturas urbanas Créditos: Pedro Andrade

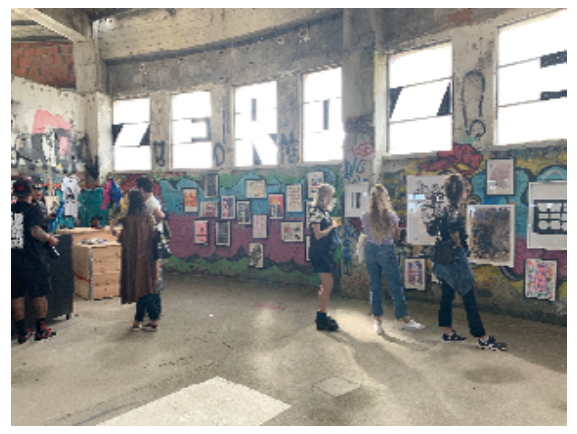

Figura 4: Pinturas na sala da associação Underdogs Créditos: Pedro Andrade

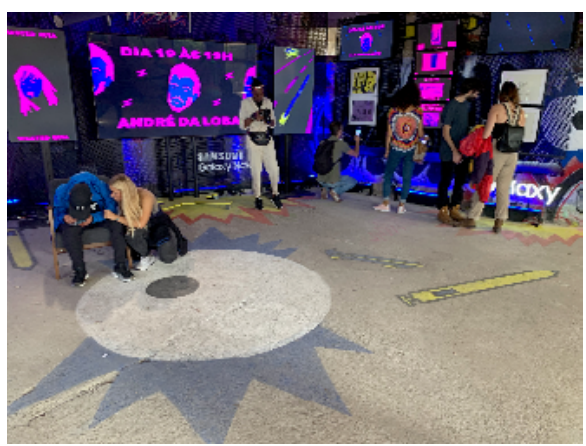

Figura 6: Comunica-ações móveis digitais Créditos: Pedro Andrade 


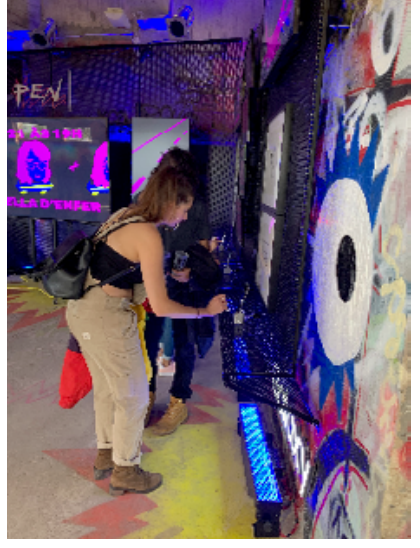

Figura 7: Consulta de saber artístico Créditos: Pedro Andrade

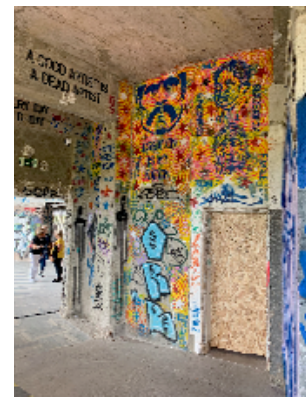

Figura 9: Artista e criatividade Créditos: Pedro Andrade

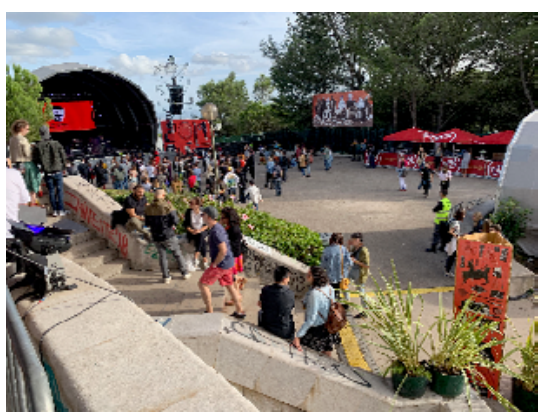

Figura 11: Música do mundo Créditos: Pedro Andrade

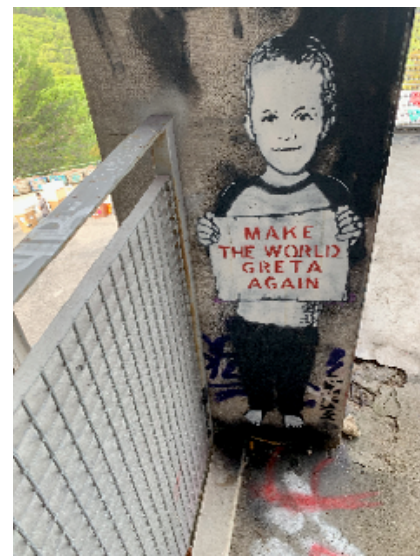

Figura 8: Great Greta

Créditos: Pedro Andrade

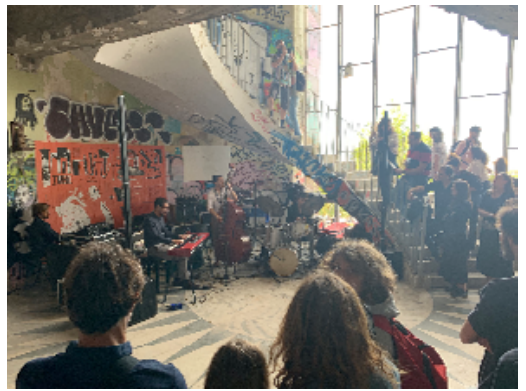

Figura 10: Jazz intercultural

Créditos: Pedro Andrade

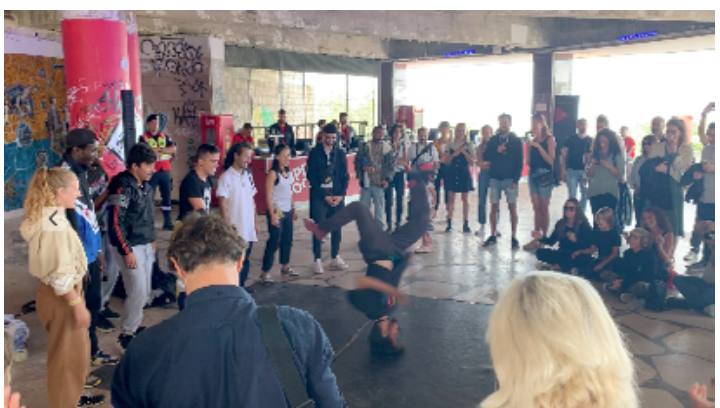

Figura 12: Break dance

Créditos: Pedro Andrade

No que respeita às artes performativas, contam-se um concerto de jazz no dia 22 de Setembro, destinado a uma audiência intercultural (Figura 10), um concerto de Música do Mundo animado pela banda árabe Mohamed Lamouri (Figura 11), em consonância com diversas outras bandas ao longo dos 4 dias do evento. Igualmente, foi possível assistir a performances de Break dance (Figura 12), um dos elementos da cultura Hip Hop além do graffiti, da música rap e do D-jing (por exemplo, performances de 
disk jocking), entre outros. Também houve imagens desenhadas no chão de uma pista de skate, no intervalo de exibições de skating.

\section{ARTE PÚbliCA DIGITAL, NO CIBERESPAÇO E NO CIBERTEMPO}

De facto, a arte pública já não é o que era na sua era pré-digital. Na contemporaneidade, em particular na última década, novas atividades criativas, agentes inventores e instituições inovadoras emergiram na internet e nas redes sociais digitais. Estes contextos digitais virtuais constituem algumas das localidades sociais e culturais que mais contribuíram para as atuais transformações e críticas da arte pública, que se tornou, em parte, uma arte pública digital.

Já em 2006 Christiane Paul notava que a "arte digital" colocou em causa as noções tradicionais da arte pública. Em particular, desenvolvendo a ideia de "bem comum na rede", a partir da interatividade entre comunidades virtuais. Uma tal partilha adquire dimensões culturais, mas também questiona as atuais noções de poder e governança. Assim sendo, a prática artística no seio da arte pública digital, articula, mas também aumenta, os espaços físico, social e virtual, de ambos esses paradigmas da esfera pública democrática.

Nestas conjuntura e conjeturas, um exemplo de arte pública digital é a instalação colaborativa, nomeada Bus-Tops, criada pelo artista plástico Mark Titchner em Janeiro de $2012 \mathrm{em}$ Londres (Minard, 2012). A obra incluiu 30 telas de LED vermelhas e pretas nos telhados de paragens de autocarros em 20 bairros da capital inglesa. O público pôde criar obras de arte nesse novo espaço de exposição, através de propostas submetidas a curadores de arte no site do projeto, que assim expande o próprio conceito de arte pública à internet. Em Portugal, entre outras ocasiões, a arte pública digital foi debatida no Congresso "Arte pública na Era da criatividade digital”, promovido por José Abreu e outros, na Universidade Católica do Porto (Abreu \& Castro, 2017).

No entanto, existem numerosas outras manifestações da arte pública digital, que diversos tipos de fontes digitais testemunham. Não tendo aqui espaço para apresentar e comentar todas elas ou mesmo as mais significativas, apresentaremos em seguida apenas uma recensão crítica sintética de parte de um projeto de pesquisa em curso, realizado sobre uma amostragem que considera fontes escritas no ciberespaço em torno de três conceitos abrangentes e centrais da arte pública: a arte, a cidade e o público. Tais termos articulam e traduzem práticas diversificadas de arte pública, ocorridas tanto no espaço público urbano quanto no ciberespaço e no cibertempo públicos. O cibertempo público define-se como o conjunto de temporalidades ativadas pelo utilizador da rede de todas as redes, quando navega no interior do ciberespaço público. Por exemplo, o tempo síncrono das conversas em linha (chats), o ritmo quase-síncrono das redes sociais digitais, ou o compasso assíncrono de um site.

Assim sendo, este projeto de investigação, em termos das fontes utilizadas, assenta na recolha da produção e disseminação de relevantes coleções de documentos digitais sobre a arte pública, inseridas paulatinamente em arquivos digitais. Um exemplo é o 
Public Art Archive2. Estes arquivos encontram-se organizados por programas de recolha e tratamento de conteúdos como o Chicago Public Art Program³. Em outros arquivos, os conteúdos de redes sociais como o Facebook, onde utilizadores se pronunciam sobre a arte pública, estão igualmente incluídos nesta coleta sistemática de fontes digitais.

Para melhor entendermos tais processos emergentes e inovadores, recorremos à seguinte metodologia, que constitui apenas um aperitivo desta problemática:

1. por um lado, em termos de recolha de dados, o corpus das fontes digitais e virtuais recolhidas e selecionadas, inclui: monografias e artigos de revistas e jornais; dicionários e diretórios; documentos governamentais, legislativos e municipais; estatísticas e gráficos; redes sociais digitais como blogues, Facebook e forae digitais; imagens e vídeos;

2. or outro lado, quanto à análise efetuada, mostram-se abaixo somente três esquemas na forma de redes concetuais, construídas com o apoio das fontes analisadas. Tais redes traduzem, social, visual e semanticamente, a contemporaneidade do tema, através da tessitura de algumas relações entre os conceitos selecionados.

Se observarmos a Figura 13, relativa ao termo "arte", repararemos que este processo sociocultural encontra-se próximo de outras ideias ou conceitos frequentes no corpus, como espaço público da cidade e, de um modo quase evidente, de projetos de artistas. No entanto, trata-se de agentes culturais que comunicam com comunidades locais, o que não sucede necessariamente no caso da arte mostrada em galerias ou museus (Public Art - Facebook City Guides, 2019) ${ }^{4}$. Outros eixos relacionais representados pelas linhas que unem os conceitos na Figura 13, esclarecem que os projetos de arte pública exibem uma estreita conexão com programas de instituições públicas ou privadas, que fornecem alguns dos fundos necessários para essas iniciativas (Public Art Fund) 5 .

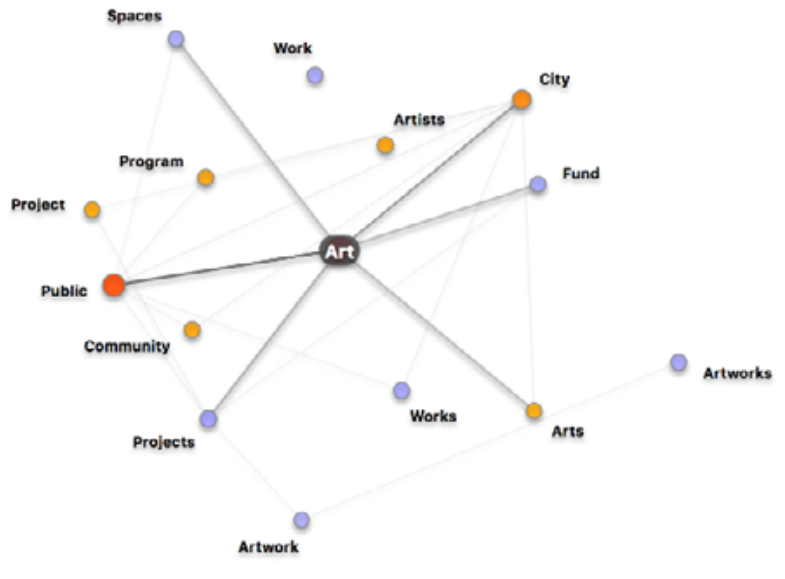

Figura 13: Rede socio-conceptual "Arte"

Créditos: Pedro Andrade

\footnotetext{
${ }^{2}$ Disponível em https://www.publicartarchive.org/

${ }^{3}$ Disponível em https://www.chicago.gov/city/en/depts/dca/provdrs/public_art_program.html

${ }_{4}^{4}$ Ver https://cityguides.fb.com/guides/lisbon-en/traditional-lisbon/public-art/

${ }^{5}$ Retirado de https://www.publicartfund.org/
} 
$\mathrm{Na}$ Figura 14, transparece a relação do espaço urbano da cidade com os planos diretores e respetivas comissões, que nos últimos anos têm privilegiado o papel do cidadão, e do cidadão cultural em especial (Chicago Public Art Program). Tal facto deve-se, em parte, à ascensão meteórica do turismo de cidade, também em Portugal, nomeadamente em Lisboa e Porto, mas que se espalha hoje para outras localidades como Braga, que ganhou recentemente um concurso internacional num projeto inserido no programa Cidades Criativas Unesco, na área Media Arts.

Em terceiro lugar, a Figura 15 torna visível, entre outras associações, o papel fundamental da constituição de coleções de obras de arte que transmitem a relevância deste género de arte ainda algo órfão e incompreendido (Public Art Archive; Public Art Resource Centre ${ }^{6}$ ). O acesso aberto a estas coleções de arte pública residentes em arquivos digitais, por parte de um público alargado, constitui um passo irreversível para o desenvolvimento da cidadania cultural democrática.

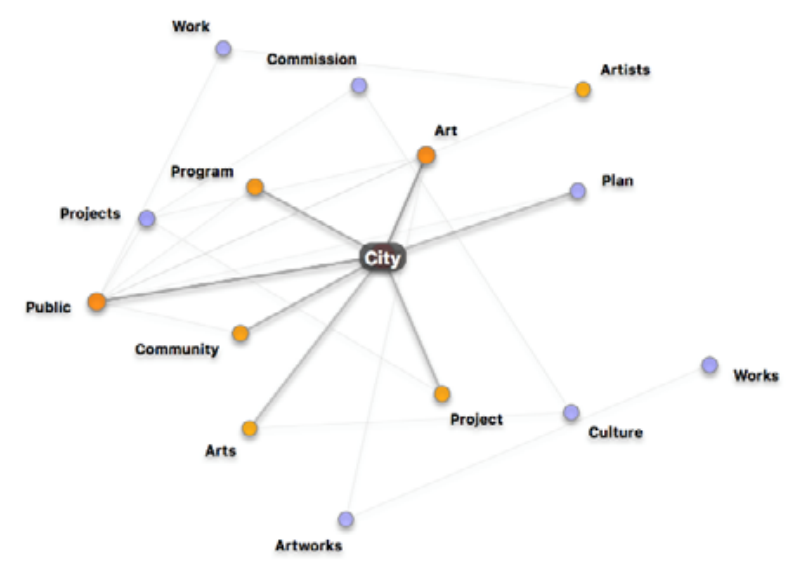

Figura 14: Rede socio-conceptual "Cidade" Créditos: Pedro Andrade

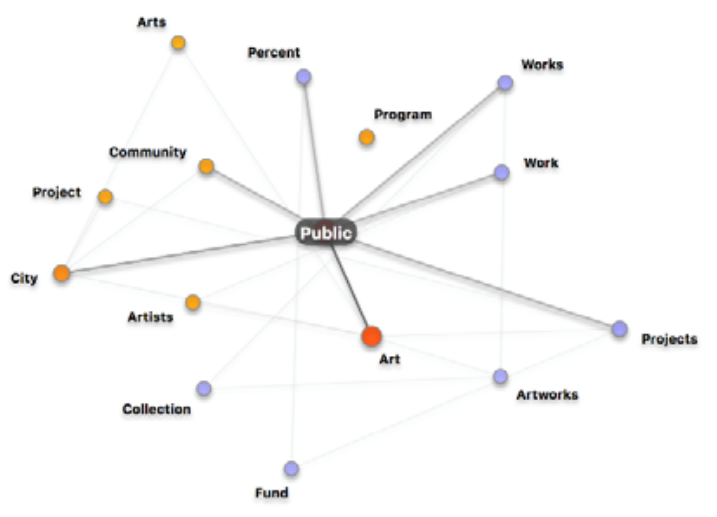

Figura 15: Rede socio-conceptual "Público"

Créditos: Pedro Andrade

6 Disponível em public-art-resource-center https://www.americansforthearts.org/by-program/networks-and-councils/public-artnetwork/ 


\section{EMBATES E DEBATES SOBRE A COMUNICAÇÃO TURÍSTICA}

Em seguida, enquanto passo argumentativo intermédio para a aplicação da arte pública ao turismo, importa agora considerar as problemáticas subjacentes a possíveis discussões, teóricas e práticas, visando a circunscrição da comunicação turística, no interior das culturas móveis e do turismo cultural.

\section{A SOCIOLOGIA DA VIAGEM}

O fenómeno da viagem não se esgota no turismo. As atividades turísticas constituem um processo social e comunicativo que propulsionou uma das indústrias do lazer e culturais mais pujantes do final do século XX. Em termos reflexivos, o turismo suscitou problematizações notáveis por parte de autores paradigmáticos da Sociologia do Turismo (MacCannell, 1976; Cohen, 1979).

Numa perspetiva histórica, o turismo constitui o paradigma dominante da viagem nas sociedades industriais, democráticas e subscritoras da modernidade. Mas nem sempre o turismo foi o modo predominante de deslocação em todas as épocas da aventura e diáspora humanas. Para demonstrar esta tese, no quadro mais abrangente de uma Sociologia da viagem (Andrade, 1993), é necessário delimitar os tipos, configurações e inerentes modos de comunicação mais significativos da viagem (deslocações de trabalho, de lazer, políticas, científicas, culturais, artísticas, religiosas, entre outras categorias), inserindo-se o turismo no interior da viagem de lazer.

Para além disso, ao exercer a crítica de certos tipos de turismo, e igualmente de uma sua alternativa, o pós-turismo (isto é, a figura turística mais típica da pós-modernidade), é possível extrair os fenómenos mais recentes que superam tanto o turismo moderno quanto o turismo pós-moderno: por exemplo, o turismo crítico, ou seja, a crítica, através de vários modos de comunicação, que o turista de um país central empreende sobre a sociedade de partida, antes, durante e após o contato com uma sociedade periférica visitada. Ou o contra-turismo, isto é, o processo político e comunicativo de resistência por parte das populações visitadas, muitas vezes em sociedades não-ocidentais, ao turismo de massas. Ou ainda a inter-viagem, uma espécie de percurso híbrido onde são visíveis fragmentos de outras formas de caminhos, e manifestações, cada vez mais omnipresentes, de ritmos comunicativos genuinamente quotidianos e localizados.

Em suma, a reflexão e tipologia da viagem operadas pelo cientista social, articuladas à crítica da viagem de turismo em particular, proposta igualmente pelos atores sociais envolvidos em atividades turísticas, esclarece alguns modos de comunicação turística possíveis, situados algures entre o turismo cultural e as culturas turísticas.

\section{TURISMO POPULAR URBANO E CULTURA TURÍSTICA NO MOVIMENTO EXCURSIONISTA F ALMOÇARISTA}

Nos Estudos do Turismo, não abundam textos sobre o turismo popular, em particular aquele promovido pelas classes populares urbanas, ou para seu usufruto (Barton, 2011). 
Todavia, existe um fenómeno português pioneiro e notável nesta área, os grupos excursionistas e/ou almoçaristas e/ou jantaristas, que se pode entender como uma das expressões mais precoces de cultura e comunicação turística (Andrade, 1986). Configuram-se como associações populares, constituídas maioritariamente por operários, funcionários públicos, empregados de empresas e pequenos comerciantes. Estes grupos possuem uma caixa comum, sustentada sobretudo por quotas dos aderentes, em vista a permitir a realização de excursões de lazer e turísticas, e de almoços coletivos periódicos, mensais, trimestrais, semestrais ou anuais, onde vários modos de comunicação se sobrepõem (conversas, comensalidade na refeição, etc.). Comunicam igualmente com os habitantes do seu bairro, na figura socioeconómica de assistência aos necessitados do próprio Grupo ou a pessoas do seu bairro. Ocorrem principalmente nas grandes cidades Portuguesas, como Lisboa, Porto, etc.

De entre as iniciativas destas associações populares, a arte excursionista constitui um tipo de experiência de comunicação artística peculiar e original, que reúne principalmente os quadros criados por membros dos grupos excursionistas, ou por outros habitantes, residentes no bairro ou em outras zonas da cidade. Trata-se de obras normalmente pictóricas, incluindo também fotografias e colagens de objetos, que são expostas nas tabernas que servem de sede ao grupo. Em termos comunicativos, os quadros operam a publicidade do grupo diante dos frequentadores das tascas, funcionando como emblemas simbólicos ou imagens de propaganda e prestígio, identitários ou diferenciais, desses clubes de amigos.

Em síntese, o movimento excursionista desvela um segundo modo de comunicação turística, no seio dos contatos e contratos entre o turismo cultural e as culturas turísticas.

\section{FLUXOS DE ARTES MÓVEIS E MOBILIDADES TURÍSTICAS NO MUSEU}

Um terceiro elemento para a circunscrição dos modos de comunicação turística, no quadro da dialética entre o turismo cultural e as culturas turísticas, é o museu de arte, na medida em que se propõe e frequentemente impõe-se como um dos pilares fundamentais da indústria turística hodierna. Esta indústria global assenta e reproduz-se no processo recente de expansão exponencial das mobilidades urbanas. O termo "mobilidade" contém um grande número de conotações. Não surpreendentemente, as direções de pesquisa sobre este assunto revelam-se incomensuráveis (Adey, Bissell, Hannam, Merriman \& Sheller, 2014).

Num tal contexto social, mostra-se útil concentrar a discussão no conceito mais restrito de "mobilidades de turismo". Considere-se aqui tão-somente os fluxos comunicativos e artísticos móveis que os turistas culturais desenvolvem durante as visitas que realizam nos museus de arte, ao mesmo tempo que transportam as suas culturas turísticas adquiridas em viagens anteriores. Tais fluxos comunicativos, em primeiro lugar, são condicionados pelas características sociodemográficas do turista (idade, género, profissão, etc.). Em segundo lugar, esses fluxos circunscrevem carreiras turísticas, delimitadas 
parcialmente pela articulação entre, de um lado, o curso do tempo da visita ao museu pelo turista e, de outro lado, os seus percursos espaciais (caminhos para uma pintura interessante, trajetórias para os serviços do museu como a loja ou o bar, etc.).

Nesta perspetiva, dever-se-ão sublinhar alguns pedestais para uma discussão urgente a desenvolver: a) a genealogia do fenómeno histórico e social "mobilidade"; b) o fenómeno particular das mobilidades de turismo; c) as mobilidades turísticas entendidas enquanto fluxos comunicativos, culturais e artísticos no museu, ou seja, como manifestações do turismo cultural móvel (Andrade, 2018b).

\section{REPRESENTAÇÕES PÓS-COLONIAIS E TRANSCULTURALISMO EM VIAGENS DISCURSIVAS NO CINEMA}

Igualmente, poderá ser frutífera, para a compreensão do fenómeno sociológico da comunicação subjacente à viagem cultural e à cultura da viagem, a articulação entre as teorias e conceitos pós-coloniais e as análises/interpretações baseadas em exemplos de imagens de filmes que testemunham e comunicam representações pós-coloniais da cultura e da viagem, produzidas/reproduzidas tanto por países colonizadores quanto por povos colonizados. Algumas destas deslocações assim transmitidas e comunicadas aos espetadores de cinema, são a epopeia política de conquista, o tráfico de escravos, as diásporas de etnias inteiras devido a guerras, a imigração dos países periféricos para os países ocidentais. Pode ser elucidativo comparar, igualmente no plano da discursividade, estas odisseias que traduzem relações sociais de desigualdade entre os povos, com outras trajetórias que do mesmo modo impõem relações desiguais, como o turismo de massas, e a forma de comunicação entre turistas e "nativos", sejam estes populações e povos não-ocidentais ou autóctones da Europa do Sul.

Na verdade, o "choque de civilizações" circunscrito por Samuel Huntington (2011), muitas vezes funciona como um conflito de significados, subjacente a todos os modos de comunicação de mensagens, em maior ou menor grau, incluindo a transmissão e partilha de mensagens turísticas.

Segundo Homi Bhabha (2004), a resistência discursiva contra o colonialismo apoia-se frequentemente na mobilização da hibridação. E para Nestor Canclini (2005), as culturas contemporâneas são essencialmente culturas híbridas. Uma tal natureza híbrida encontra-se presente em muitas imagens comunicadas pelo cinema de resistência, e é urgente sublinhar as suas características, por exemplo oposições ou hibridações discursivas centrais transmitidas pelos autores do cinema transcultural: "colonizador/ colonizado", "identidade/diferença", "poder/não poder".

Quanto aos modos de comunicação acionados pelas audiências cinematográficas, nas salas de cinema ou na internet, os públicos do cinema de resistência podem ver e criticar, de forma menos ou mais participativa, as visões de mundo e discursos transmitidos pela imaginação cinematográfica, e em particular pelo militantismo no cinema, contribuindo para um fundo e arquivo da memória comum e global das culturas populares e do conhecimento críticos. Algumas destas culturas circunscrevem-se parcialmente 
enquanto culturas turísticas que, embora condicionadas pelo turismo cultural dominante, também por vezes o influenciem, igualmente no que respeita os modos de comunicação em jogo (Andrade, 2016).

\section{E-TURISMO CULTURAL E DISCURSO DIGITAI}

Um outro enlace entre o turismo cultural e as culturas turísticas ocorre no ciberespaço e no cibertempo, em especial quanto aos correspondentes modos de comunicação turística.

De facto, é necessário levar a sério o desafio que a internet está a colocar aos estudos do Turismo Cultural e à Sociologia da Comunicação e das Artes. As narrativas sociológicas que tomam esse desassossego em consideração, fundam-se, em parte, no conceito seminal de mobilidades, mas confrontam-no com outras posturas teóricas, conceituais e empíricas recentes.

Como se alertou supra, é preciso descortinar um plano de fundo teórico que identifique o estado da arte das discussões sobre os conceitos associados às mobilidades culturais urbanas (Urry, 2007). Em particular, urge repensar as novas formas de visibilidade social envolvidas nas mobilidades e modos de comunicação turísticas, seja por parte dos turistas em relação às sociedades visitadas, seja nas figuras do olhar delineadas pelos habitantes em relação aos turistas (Urry \& Larsen, 2011). De facto, as mobilidades do turismo cultural conectadas às culturas turísticas, constituem alguns dos mais influentes processos sociais e noções sociológicas que contextualizam o e-turismo cultural ativado na internet, e os discursos e conteúdos inovadores aí produzidos, reproduzidos e comunicados sobre esta problemática.

Simultaneamente, impõe-se um debate sobre o património cultural, em encontro e confronto com o e-turismo cultural. Para além disso, emergem hoje controvérsias relevantes que articulam o turismo com os novos media e as redes sociais digitais. Trabalhos futuros poderão e deverão incluir formas concretas e inovadoras de e-turismo atuantes em redes discursivas não apenas em cidades europeias ou americanas, mas igualmente no seio de diversas urbes do tecido social africano, asiático ou australiano.

Em particular, diversos ensaios e pesquisas estudaram contextos e processos centrais para o desenvolvimento do turismo cultural em linha, como os museus virtuais em Portugal inseridos na sociedade em rede mundial, por exemplo sobre as seguintes aspetos: viagens virtuais e virtualidades da ciberviagem (Andrade, 1997), e-art em museus virtuais (Andrade, 2005); cibermuseus e cibermuseologia (Andrade, 2006); museus digitais e Web 2.0 (Andrade, 2008); lazeres e saberes em museus e cibermuseus da cidade criativa (Andrade, 2009); virtualidades do museu e museus virtuais (Andrade, 2010c); museus virtuais e artes digitais (Andrade, 2015a).

Em suma, o e-turismo ou turismo cultural eletrónico e a cultura turística em torno dos museus virtuais, podem constituir poderosas estratégias vindouras de modos de comunicação turística, por forma a melhorar a inovação discursiva nas redes de património cultural digital. E, ao fazê-lo, motivar futuras pesquisas originais na Sociologia da Comunicação, Cultura, Artes e Turismo (Andrade, 2017). 


\section{EPISTEMOLOGIAS, TEORIAS, METODOLOGIAS F FONTES PARA O ESTUdO DA ARTE PÚBLICA APLICADA À COMUNICAÇÃo TURÍSTICA}

Os debates epistemológicos, teóricos e metodológicos que visam credibilidade científica não podem prescindir da correspondente aplicação ao tecido social. Inversamente, os processos societais deverão sempre informar a reflexão. No caso da arte pública, registaram-se profundas transformações nas últimas décadas, em particular no seio do processo de constituição da arte pública digital, fenómeno mencionado e desenvolvido supra. Num tal contexto, a arte pública poderá ser analisada por diversos géneros sociológicos, para além daqueles mais tradicionais, no que respeita à teoria, à metodologia e às fontes empíricas aplicadas em projetos de investigação.

Em especial, a arte pública, e em particular a arte pública digital, bem como a sua natureza epistemológica, ou as teorias e metodologias aplicadas aos estudos sobre ela, adquirem novas roupagens na chamada Web 2.0 ou Web social, que inclui as redes sociais digitais, como o Facebook, Instagram, WhatsApp, etc. Sucintamente, a Web 2.o define-se como uma segunda etapa, idade ou era da Internet, em que os seus conteúdos não são apenas produzidos pelos autores de um sítio ou rede, mas igualmente pelos seus utilizadores. Nos inícios (na chamada Web 1.0), a internet apenas permitia a autoria por um número reduzido de pessoas (programadores, quadros dos setores público e privado etc.), e a maioria dos visitantes somente consultava os conteúdos expostos. Agora, qualquer infonauta pode ler e escrever (comentários em blogues, anotações e avaliações de páginas Web, etc.), no ciberespaço e no cibertempo. Assim sendo, a Web 2.0 é também nomeada "internet de leitura-escrita".

No entanto, embora as redes sociais da Web 2.0 sejam extremamente populares, para muitas pessoas, as suas caraterísticas profundas e o próprio termo Web 2.0, ainda mantém uma certa aura de estranheza, de alteridade, da mesma forma que a arte pública ainda não é considerada tão legítima quanto a arte privada dominante, embora a primeira se encontre a cada passo e esquina das cidades contemporâneas.

\section{Novas metodologias sociológicas: Sociologia Artística E Hibridologia}

Assiste-se hoje à emergência de metodologias inovadoras, no seio dos diversos modos e meios de conhecimento, como alerta Patricia Leavy (2009, p. 18), ao aproximar a pesquisa sociológica da prática artística: "trabalhar com metodologias inovadoras muitas vezes exige que os pesquisadores atravessem fronteiras disciplinares, deixem as suas zonas de conforto...". Dito de outro modo, os encontros entre diversas configurações de saberes podem passar do conforto para o confronto. Uma destas áreas simultaneamente de desconforto e de criatividade nas Ciências Sociais é a Sociologia Artística (Andrade, 2018a, pp. 248-249), entendendo-se como um saber híbrido que mescla a razão com as sensações, ao pronunciar-se sobre as atuais realidade e sociedade híbridas.

A conjunção de todos os saberes híbridos nomeia-se Hibridologia (Andrade, 2014; 2015b). Esta nova sensibilidade das Ciências Sociais e Humanas usa métodos híbridos, ou seja, procedimentos de investigação de diferente natureza, utilizados simultaneamente 
ou articulados entre si, por exemplo no uso conjunto de técnicas científicas, tecnológicas e artísticas. Para tal, os métodos híbridos apoiam-se em media híbridos ou hibrimédia, termo que significa a fusão dos media de diferente natureza, usados seja em copresença de vários indivíduos num lugar físico, seja através das comunicações de massa, seja por meios digitais. Por exemplo, o conteúdo de um médium inicial (uma notícia de jornal ou uma fotografia) pode ser comentado e misturado com fontes de outra natureza como vídeos num blog, produzindo assim um médium de natureza mista e híbrida, um todo que não se confunde com a soma das partes. Por outras palavras, media originários podem produzir e disseminar um médium original.

Dentro da Sociologia Artística, da Hibridologia ou de outras propostas alternativas do trabalho sociológico, revela-se fundamental o trabalho de campo empírico no quadro da comunicação cultural urbana na cidade 3.0 e na cultura 3.0 (Sacco, 2011), ou no turismo 3.0 (Richards, 2011). Para além disso, revela-se fundamental refletir sobre a comunicação turística no contexto do turismo comunicativo. Este tipo de turismo assenta num paradigma das atividades turísticas centrado na comunicação turística que se estabelece entre três dos principais agentes da contemporaneidade transcultural: cidadãos, turistas e imigrantes das sociedades periféricas deslocados nas sociedades centrais. Para mais pormenores e definições dos termos acima introduzidos, em relação com outros conceitos, ver o glossário em anexo e Andrade (2018a, pp. 253-254).

Um dos lugares onde a cidade, a cultura e o turismo 3.0 se desenvolvem é a denominada Web 3.o por Tim Berners-Lee, o fundador igualmente da World Wide Web. A Web 3.0 ou Web social-semântica, embora sendo uma rede social digital, revela-se também uma rede semântica, na medida em que faculta significados sobre as ações e palavras ditas pelos seus utilizadores que se encontram em conexão reticular, de um modo mais profundo do que sucede na Web 2.o. Uma tal produção intensa de sentidos ocorre seja de um modo mais quantitativo (mais cobertura de denotações objetivas), seja de maneira mais qualitativa (maior profundidade e rigor das conotações subjetivas). Alguns exemplos pioneiros são a Wikipédia ou os wikis em geral e o projeto "Freebase", recentemente adquirido pela Google.

Para além disso, a exposição NewArtFest'17 funcionou enquanto palco da aplicação de abordagens metodológicas sociológicas e artísticas inovadoras. Este evento cultural decorreu entre 1 e 30 de novembro de 2017, no espaço da Sala do Picadeiro do Museu Nacional História Natural e de Ciência, em Lisboa, coordenado pelo curador cultural António Cerveira Pinto e pela equipa da empresa cultural Ocupart. Numa primeira etapa, a Exposição Sociológica sobre Turismo 3.0 / Cidade 3.0, que ocorreu naquele espaço, mostrou e demonstrou os saberes urbanos e da viagem, no seio do espaço da galeria de arte pública. Numa segunda fase, este saber testado no público da exposição, foi reintroduzido num artigo científico (Andrade, 2018a, pp. 261-269). Um tal duplo movimento de pesquisa hibridiza e confronta, em moldes ao mesmo tempo originários e originais, o conhecimento e a prática científicos e artísticos.

Neste contexto, alguns exemplos de novos métodos e técnicas da Sociologia aplicados à arte pública e à comunicação turística são os seguintes: o inquérito visual-virtual, 
ou seja, um inquérito visual utilizando vídeo digital, incluindo questões colocadas a políticos internacionais sobre a cidade, a sua cultura e as artes públicas; a galeria sociológica virtual, que, a partir de um telemóvel, e usando realidade aumentada, permite a consulta de informação e conhecimento sociológicos sobre arte pública, num site; e a banda desenhada sociológica, que explanaremos a seguir.

\section{O método Sociological Comics}

No interior da Sociologia Artística, os Sociological Comics constituem uma banda desenhada onde se realiza uma pesquisa sociológica através de visualidades sociais, como a prática das fotografias digitais obtidas através do telemóvel, por forma a desvelar a visibilidade social dos fenómenos societais no tecido urbano, por exemplo a arte pública e a comunicação turística. A primeira banda desenhada sociológica versou sobre o processo das lutas sociais políticas contra a austeridade em Portugal de 2013, testemunhado através de fotografias sobre esse fenómeno, que utilizou a arte pública em diversas das suas configurações, como os murais e os cartazes, ou a arte pública digital e virtual, que circulou nas redes sociais do ciberespaço e do cibertempo (Andrade, 2015c).

No dispositivo social, político, cultural e artístico dos Sociological Comics, são convocados três tipos de meios e métodos de comunicação: em primeiro lugar, o modo de comunicação em copresença (manifestações políticas, murais, graffitis, stenceis, stickers, etc.); em segundo lugar, o regime de comunicação através dos meios de comunicação clássicos, como os jornais e a televisão; finalmente, o sistema mediático de comunicação digital, no seio das redes sociais digitais Facebook, Twitter, YouTube, Instagram ou Pinterest. Todas estas estratégias comunicativas podem ser visionadas e comentadas por cidadãos, turistas e imigrantes.

Em particular, um tal dispositivo, nos seus prismas científico e literário, revela-se um método sociológico inovador, que aproxima o conhecimento sociológico às histórias e saberes sociais, por meio de uma história sociológica apresentada na forma de banda desenhada. Por outras palavras, esta banda desenhada sui generis funda-se numa estratégia epistemológica que permite, ao cientista social, realizar uma pesquisa sociológica através de diversas técnicas específicas, tais como: a demonstração de hipóteses a partir da sua validação/infirmação no campo empírico do espaço público urbano (ruas, praças, etc.); a utilização de jogos sociais de linguagem, incluindo críticas ou humor por parte do cidadão comum e recolhidos pelo sociólogo; o uso de hibrimédia (isto é, média hibridizados) no seio das redes sociais digitais.

Recentemente, a metodologia do Sociological Comics foi aplicada aos Estudos do Turismo, em ensaios sobre o turismo cultural observado através de dispositivos locativos, como o telemóvel (Andrade, 2020a, 202Ob).

\section{Conclusão}

Muito mais seria possível dizer. Por agora, retenha-se que a compreensão da arte pública para a comunicação turística, terá que ser empreendida em equipas de 
investigação transnacionais e multiculturais. Só assim se poderá entender a progressiva centralidade da arte pública nas redes dos mundos da arte, de cidadania e do turismo, e em particular no seio de jogos de conflito, mas também jogos de consenso, entre diferentes identidades e convergentes alteridades, como os jovens, as mulheres, os imigrantes, etc.

Em suma, a teoria não se pode apartar da prática sobre a arte pública e os modos de comunicação social em geral e turísticos em particular. Numa ótica dialógica inspirada em Paulo Freire, parece-nos que os poderes públicos deverão comunicar mais com os artistas, ambos com o cidadão comum, estes com o investigador e o pedagogo da cidade, e todos com as diferentes figuras da alteridade e da interculturalidade como o turista e o imigrante que, cada vez mais, fazem parte das nossas sociedades e culturas contemporâneas glocalizadas, isto é, simultaneamente planetárias e locativas e, no futuro, possivelmente menos exclusivas e mais inclusivas.

\section{Agradecimentos}

Este trabalho é apoiado por fundos nacionais através da FCT - Fundação para a Ciência e a Tecnologia, I.P., no âmbito do Financiamento Plurianual do Centro de Estudos de Comunicação e Sociedade 2020-2023 (que integra as parcelas de financiamento base, com a referência UIDB/00736/2020, e financiamento programático, com a referência UIDP/00736/2020).

\section{REFERÊNCIAS}

Abreu, J. \& Castro, L. (Eds.) (2017). Arte pública na era da criatividade digital: atas do colóquio internacional 2017. Porto: Universidade Católica Editora.

Adey, P. Bissell, D., Hannam, K., Merriman, P. \& Sheller, M. (Eds.) (2014). The Routledge handbook of mobilities. Londres: Routledge.

Andrade, P. (2020a). Cultural tourism and mobile digital devices: an analysis of tourists in Lisbon through sociological comics and video paper. In C. Sarmento \& Quincé (Eds.), Intercultural routes across multicultural spaces: from theory to dialogue (pp. 39-56). Porto: Centro de Estudos Interculturais.

Andrade, P. (2020b). Rua Augusta, um espaço intercultural: comunicação turística via media locativos para a sustentabilidade territorial. In P. Romoaldo et al. (Eds.), Livro de Atas do XII Congresso da Geografia Portuguesa: Geografias de transição para a sustentabilidade (pp. 326-331). Guimarães: Universidade do Minho.

Andrade, P. (2018a). Epistemologia e metodologia do turismo cultural urbano: o caso da Sociologia Artística das culturas móveis e da comunicação turística em redes sociais urbanas. Revista de Comunicação $e$ Sociedade, 33, 215-242.

Andrade, P. (2018b). Mobile art flows: tourism mobilities at the museum. In E. Araújo, R. Ribeiro, P. Andrade \& R. Costa (Eds.), Viver em/a mobilidade: rumo a novas culturas de tempo, espaço e distância. Livro de atas (pp. 193-198). Braga: CECS. 
Andrade, P. (2017). Cultural e-Tourism depicted by digital discourse: the case of Portuguese networks of e-heritage and discursive innovation. In M. Bielenia-Grajewska \& M. Ríos (Eds.), Innovative Perspectives on Tourism Discourse (pp.1-17). Hershey: IGI Global.

Andrade, P. (2016). Transcultural cinema debated in a knowledge network: postcolonial hybrid meanings within resistance cinema, Comunicação e Sociedade, 29, 395 - 411.

Andrade, P. (2015a). Musées virtuels et arts numériques. In M. Veyrat (Ed.), 110 Notions sur les Arts Numériques (pp. 179-80). Paris: Les Éditions de l'Immatériel.

Andrade, P. (2015b). Hybridologie. In M. Veyrat (Ed.), 110 Notions sur les Arts Numériques (pp. 127-8). Paris: Les Éditions de l'Immatériel.

Andrade, P. (2015c). Austerity (Hi)story through sociological comics: a guide to social media and networks against austeritocracy for use by all generations. North Charleston: Create Space.

Andrade, P. (2014). Post-colonial Co-ordinary literature and Web 2.0/3.0: thinking back within transmediatic knowledge. In M. Pope (Ed.), New literary hybrids in the age of multimedia expression: crossing borders, crossing genres (pp.123-144). Amsterdão: John Benjamin Press.

Andrade, P. (2012). Sociology of metaverses: virtual worlds as public and private spaces and cyberspaces. In F. Negri (Ed.), Público e privado na época contemporânea (pp. 311-329). Lisboa: Centro de Estudos Comparatistas, Faculdade de Letras da Universidade de Lisboa.

Andrade, P. (2010a). Introdução. In P. Andrade, C. Marques \& J. Barros (Eds.), Arte pública, cidadania: novas leituras da cidade criativa (pp. 13-30). Lisboa: Edições Caleidoscópio.

Andrade, P. (2010b). Arte pública versus arte privada? Alteridades artísticas urbanas e Web 2.o. In P. Andrade, C. Marques \& J. Barros (Eds.), Arte pública e cidadania: novas leituras da cidade criativa (pp. 4467). Lisboa: Edições Caleidoscópio.

Andrade, P. (2010c). Virtualidades do museu e museus virtuais. In P. Andrade (Ed.), Museus, públicose literacia científico-tecnológica: redes sociais de comunicação de significados no espaço interdimensional do mиseu (pp. 145-149). Lisboa: Ed. Colibri.

Andrade, P. (2009). Cidadania cultural e literacia artística: lazeres e saberes em museus e cibermuseus da cidade criativa. Comunicação e Sociedade, 14, 51-59.

Andrade, P. (2008). Web 2.0 and digital museums. In L. DeFonso (Ed.), Psicologia e Estética no futuro (pp. 56-60). Chicago: Baywood.

Andrade, P. (2006). Cybermuseus e cibermuseologia: o hybrilog como um Bloseum. In H. Gottesdiener \& J. Vilatte (Eds.), Culture and Communication (pp. 553-557). Avignon: International Association of Empirical Aesthetics.

Andrade, P. (2005). Art/Science/Technology - e-art in virtual museums measured by interdimensional networking method. In J. Fróis, P. Andrade \& F. Marques (Eds.), Art and science - Proceedings of the XVIII Congress, International Association of Empirical Aesthetics (pp. 59-64). Lisboa: International Association of Empirical Aesthetics.

Andrade, P. (1997). Navegações no cibertempo: viagens virtuais e vitualidades da ciberviagem. Atalaia, 3, $111-124$.

Andrade, P. (1993). Sociologia da viagem: deslocações diárias e anti-quotidiano nómada. Revista Crítica de Ciências Sociais, 37, 51-77.

Andrade, P. (1986). A arte Excursionista. Colóquio-Artes, 68, 5-11. 
Barton, S. (2011). Working-class organizations and popular tourism, 1840-1970. Manchester: Manchester University Press.

Bhabha, H. (2004). The location of culture. Londres: Routledge.

Canclini, N. (2005). Hybrid cultures: strategies for entering and leaving modernity. Minneapolis: University of Minnesota Press.

Cohen, E. (1979). A phenomenology of tourist experiences. Sociology, 13, 179-201.

Conde, I. (2010). Contrasting narratives: art and culture in the public sphere. In P. Ahonen, S. Hanninen \& K. Palonen (Eds.), Fortunae rota volvitur: studies on the writings and other work on Ilka Heiskanen (pp. 276287). Helsínquia, The Finnish Political Association.

Harvey, D. (1990). The condition of postmodernity: an enquiry into the origins of cultural change. Cambridge, MA: Blackwell.

Huntington, S. (2011). The clash of civilizations and the remaking of world order. Nova lorque: Simon \& Schuster.

Leavy, P. (2009). Method meets art: arts-based research practice. Nova lorque: The Guilford Press.

MacCannell, D. (1976). The tourist: a new theory of the leisure class. Nova lorque: Schocken Books.

Minard, J. (2012, 11 de janeiro). London 2012: olympic-inspired art to light up bus stops. BBC News. Retirado de https://www.bbc.com/news/entertainment-arts-16510085

Paul, C. (2006). Digital art/public art: governance and agency in the networked commons. First Monday: peer reviewed journal on the Internet, 7. Retirado de https://firstmonday.org/ojs/index.php/fm/article/ view/1616/1531

Peace, S. (2020). Abstract Art Images \#9, during Covid-19: Making Art while Cocooning. [s.n].

Richards, G. (2011). Creativity and tourism: the state of the art. Annals of Tourism Research, 38(4), 1225-1253.

Sacco, P. (2011). Culture 3.0: a new perspective for the EU 2014-2020 structural funds programming. Bruxelas: European Expert Network on Culture.

Urry, J. (2007). Mobilities. Cambridge: Polity Press.

Urry, J. \& Larsen, J. (2011). The tourist gaze 3.0. Thousand Oaks: Sage.

\section{APÊNDICES}

\section{GLOSSÁRIO BREVE SOBRE ARTE PÚbLICA URBANA E COMUNICAÇÃo TURÍSTICA}

Arte pública: manifestação artística produzida, exposta, percecionada, julgada e praticada na esfera pública, por ex. em sítios urbanos públicos (ruas, praças, etc.); nos meios de comunicação de massa, como os jornais, rádio e televisão; e no ciberespaço/ cibertempo.

Arte pública digital: sub-género de arte pública, criada, operada e disseminada no ciberespaço/cibertempo. 
Cidade 3.o: ou cidade social-semântica: localidade globalizada e configurada numa rede urbana geográfica que inclui redes digitais, sociais mas também semânticas, caraterísticas da Web 3.0, em particular nas atividades do Turismo 3.0.

Cidade inteligente (smart city): paradigma de cidade que privilegia a planificação, a monitorização e as tecnologias digitais, no sentido de obtenção de maior previsibilidade na restruturação urbana, entre outros aspetos em termos de maior mobilidade e segurança no espaço público. No entanto, esta visualização ubíqua da cidade e do cidadão comporta riscos, desde a intromissão na sua vida privada, passando pelo desrespeito dos direitos humanos, até à naturalização e aceitação acrítica de um panoptismo generalizado.

Cidade criativa: modelo de espaço urbano que aproxima a cultura, a criatividade e a transformação da cidade. Esta postura destaca, entre outros processos e práticas: o interculturalismo nas cidades, a psicologia das cidades, as burocracias criativas e a medição da criatividade nas cidades.

Cultura 3.0: para além do entendimento da cultura como um produto derivado da economia industrial nos séculos XVIII e XIX (Cultura 1.0), ou da conceção da cultura como indústria cultural no século XX (Cultura 2.0), a noção de Cultura 3.0, associada às novas tecnologias digitais, significa que a cultura constitui um meio de criar identidade e valores, estimular a coesão social e incentivar a criatividade.

Cultura móvel: modo de exercer a cultura e a vida social em geral, que se transforma hoje, em parte, numa vida digital, articulada aos ritmos e lugares móveis da vida quotidiana urbana, em particular às mobilidades urbanas da cidade 3.0, da cidade inteligente e da cidade criativa, sobretudo através de dispositivos portáteis, como o computador laptop e a tablet, ou o iPod e o telemóvel.

Hibridologia: consiste no estudo científico, tecnológico e artístico, das entidades híbridas que pululam, e de certo modo definem, a nossa contemporaneidade globalizada, como no caso da hibridação demográfica crescente nas sociedades europeias, através de décadas de imigração massiva.

Métodos híbridos/hibrimédia: mistura, fusão ou hibridização de diversos métodos e media científicos, tecnológicos ou artísticos, por exemplo aqueles que caracterizam os seguintes modos de conhecimento: Ciências Sociais (questionário, etc.), novas tecnologias (dispositivos digitais interativos construídos em hipermédia) e as artes (arte objetual, arte processual como a instalação e a performance).

Públicos da arte pública: audiências que incluem características sociodemográficas específicas e desenvolvem carreiras de comunicação particulares, dentro ou fora das 
suas visitas a locais e eventos de arte pública. Por exemplo, quando esses públicos relacionam, de um lado, obras de arte pública e o espaço do museu ou de outros locais de exposição da arte pública, como a rua, praças e outras localidades citadinas, com, de outro lado, a sua própria experiência da cidade, do trabalho, da família e da escola. Alguns principais segmentos de tais públicos são estes: famílias; estudantes e professores de uma instituição de ensino; um visitante isolado ou grupos que visam realizar formação contínua ao longo da vida; o turista subscritor do turismo cultural, do turismo criativo, do turismo inovador e do turismo comunicativo. No entanto, outros perfis, ainda marginalizados, devem ser incluídos nas audiências artísticas e, em particular, nos públicos de arte pública, como os reformados, os deficientes, os imigrantes e os refugiados.

Turismo 3.0: define-se a partir dos seguintes traços: maior interesse dos turistas pelo património intangível; superação da dicotomia entre alta cultura e cultura popular, processo por exemplo testemunhado pela abertura do turista à arte pública exibida na rua; hibridação entre produção e consumo cultural; desejo de experiências autênticas na viagem turística. Um tal paradigma do turismo hodierno desvela-se como uma das manifestações práticas da Cidade 3.0, que frequentemente permite a utilização da Cultura 3.0 no seio do ciberespaço público da Web 3.0.

Turismo comunicativo: paradigma das atividades turísticas centrado na comunicação turística que se estabelece entre três dos principais agentes da contemporaneidade transcultural: cidadãos, turistas e imigrantes das sociedades periféricas deslocados nas sociedades centrais.

Turismo criativo: modelo de turismo relacionado com a criatividade das comunidades urbanas e pequenas cidades, no sentido de revitalizar a economia, a sociedade e a cultura dessas localidades, através das atividades turísticas aliadas sobretudo à pequena indústria, ao pequeno comércio e ao artesanato.

Turismo cultural: tipo de turismo que se interessa, predominantemente, por aspetos culturais de uma sociedade (artes ou outros fenómenos culturais e suas instituições ou contextos), por ex. o museu da arte pública, ou outros espaços públicos culturais, como a rua e a praça.

Turismo cultural digital (e-cultural tourism): modo do turismo associado ao ciberespaço e ao cibertempo, bem como à cultura móvel veiculada pelo turista através do telemóvel, por exemplo enquanto instrumento de ligação da arte pública à cibercultura.

Turismo inovador: género de turismo articulado à inovação social, em especial no seio das mobilidades urbanas caraterísticas da cidade inteligente (smart city).

Web 2.o (ou social web ou internet da leitura/escrita): tipo de rede social digital que permite uma postura ativa por parte do utilizador: além de ler as informações, ele pode 
escrever conteúdos como artigos (posts) ou comentários num blog, e partilhar informações pessoais e profissionais em redes sociais digitais, como o Facebook, o Twitter ou o Youtube, Instagram ou WhatsApp.

Web 3.0 ou web semântica: paradigma de redes sociais digitais que se baseia, entre outros dispositivos discursivos, em sites semântico-sociais. Ex: sites Freebase, Comunicação Pública de Arte.

\section{NOTA BIOGRÁFICA}

Pedro Andrade é sociólogo e investigador na Universidade do Minho, CECS. Ensinou, nas Universidades de Coimbra e Lisboa, Sociologia da Cultura, Comunicação, Métodos Sociológicos, Humanidades Digitais. Investigação em culturas urbanas, comunicação artística, museus de arte/ciência, literacias, redes sociais digitais (web 2.0/3.0), metodologias/hibrimédia. Coordenador de projetos internacionais, como "Literacia científico-tecnológica e opinião pública" (2005, sobre públicos de museus de Ciência) e "Comunicação pública da arte" (2011, sobre museus de arte e suas relações com audiências, turismo, metodologias digitais/virtuais, interação hibrimédia, jogos sociológicos/culturais, redes sociais, realidade virtual/aumentada), ambos financiados pela FCT. Participação em redes universitárias internacionais, como Virginia Commonwealth University, EUA; membro do projeto "Manifesto Art and Social Inclusion in Urban Communities" (Reino Unido). Autor de vários livros e artigos científicos publicados em revistas internacionais e nacionais com revisão por pares, indexadas em bases de dados bibliográficas globais (Web of Science, etc.). Diretor da primeira revista científica luso-francesa, Atalaia-Intermundos (desde 1995).

ORCID: https://orcid.org/oooo-0003-4550-0562

Email: pjoandrade@gmail.com

Morada: Centro de Estudos de Comunicação e Sociedade, Instituto de Ciências Sociais, Universidade do Minho, Campus de Gualtar, 4710-057 Braga, Portugal

\section{Submetido: 04/09/2019}

Aceite: $31 / 11 / 2019$ 